\title{
MISCELLANEA
}

\section{A Study of Variations in Output}

\author{
I. M. RICHARDSON and W. Z. BILLEWICZ* \\ From the Departments of Social Medicine and Midwifery, \\ University of Aberdeen
}

The importance to industry of variations in working efficiency and their causes has been recognized for many years. Between the wars a considerable number of investigations was sponsored by the Industrial Health Research Board and in recent years interest in output variations has increased. The approach of particular research workers has differed widely; the influence on output of hours of work, rest pauses, environmental conditions, monotony and variety of tasks, eyestrain, methods of work, shift systems, mental handicap, are only some of the factors studied. In most published papers, whatever their special approach, much attention is devoted to the several and severe difficulties inherent in the use of output figures as an index of human efficiency. After long experience in this field Wyatt (1944) stated that "factory output records must be interpreted with the greatest caution. Normally variations of output are rarely, if ever, due to a single outstanding cause ".

Broadly speaking, variations in performance are caused by a ccmbination of personal and impersonal factors. Efficiency may be disturbed by changes in materials, machines, methods of production, working conditions and other factors, without any apparent change in the physical or mental state of the worker ; on the other hand conscious or unconscious changes in the worker can alter output in the absence of any detectable change in the material and mechanical conditions of the job. Since both sets of variables are constantly interacting it can be readily understood how complex is the aetiology of output variations.

Obviously the extent to which a worker is able to control his material and machine must be an important determinant of the amount of variation. At one extreme is the situation where the influence of mechanical factors is almost negligible, as for example in some of the handcrafts, at the other is the automatic machine which requires only starting, stopping, and a constant feed of material. In all studies of output this element of control is outstandingly important.

In 1920 Wyatt reported an investigation of output variations among cotton mule spinners in which he showed that "in mule spinning the part played by the operative is very small compared with the overwhelming influence of the machine". Any technical advances in the last 30 years have tended to reduce still further the operator's control over a spinning mule. Despite this high degree of mechanization our findings show that

* Obstetric Medicine Research Unit, Medical Research Council. individual differences between workers can be an important source of output variation.

\section{Method of Study}

We were fortunate in having free access to a modern woollen mill where for five years a production-study department had been developing. The aim of this department was to establish a sound scheme of paymentby-results based on work-study techniques ; after intensive study of the duties of "piecers" (the name given to operators of spinning mules), standard times per unit of material had been calculated and a formula devised which measured output in performance units per week. These operator performance figures are hereafter referred to as O.P.

Weekly O.P. figures for 36 operators (33 women and three men) were collected from production-study records which were scrutinized while "hot", i.e., at the end of each week, and, with technical assistance, notes were made about any mechanical or material peculiarities. Although the O.P. formula was designed to equalize operators in respect of both these factors, and probably did so with small peculiarities, we decided to reject all O.P. figures for weeks in which a major mechanical breakdown or exceptional quality of wool had been recorded. By so discarding 26 O.P.s the amount of variation due to non-human sources has been reduced; we are satisfied that any remaining variation due to these factors is probably of minor importance and would in any case have affected all operators in the same degree.

The average period of observation per operator was 33 weeks. Absence records were kept throughout the study and for all absences of one week or longer medical evidence was available. This "health" information was supplemented by a personal interview with each worker at the end of the study ; no medical examination was carried out, but subjective health (including any symptoms or disabilities) was assessed by careful questioning. One of us knew most members of the group in advance and was therefore able to establish good rapport at this health interview. None of the group was aware that we were observing their output, the interview being presented as part of a normal interest in occupational health.

It must be emphasized that our study was concerned with individual performance, not with variation in the weekly production of the spinning department as a whole. By weekly output figures are meant the performances of the 36 operators selected for study during the weeks when they were at work.

\section{Findings}

Operators were divided into two groups: (1) 29 operators in good health and (2) seven operators whose 
physical condition suggested a possible source of output variation. This group comprised a totally deaf girl, a middle-age woman with hypertension, an elderly man severely disabled by emphysema, and four pregnant women.

The Effect of Experience.-The two groups were subdivided according to length of experience in piecing. Six experience groups were distinguished: first year, second year, third year, fourth and fifth years, sixth to fourteenth year, and fifteenth year or more. We chose this grouping partly in the belief that small differences in experience are likely to be more important at the beginning of an operator's career whereas wider grouping is permissible with more experienced workers, and partly because it gave groups of roughly even size.

Table 1 shows the mean O.P. and standard deviation for each of the 29 healthy operators grouped by length of experience. The data show that average weekly performance tends to rise as experience increases. This upward trend may be due in part to a selection effect, the less efficient operators having dropped out in the first few years leaving their more skilled contemporaries to move on into the upper experience groups. If this had been happening the comparison between lengths of experience may be false but against this view is the fact that only those operators who, during training, showed promise of becoming proficient, were allowed to become production piecers; this policy "weeded out" the least efficient and must have reduced the selection effect here considered.

In the further analysis we have omitted records of the three girls with only one year of experience. In the mill it was well known that, after her training period with an experienced piecer was over and she was given a mule of her own, a girl's performance improved rapidly in the first few weeks of independent work. This improvement shows in production records not only as rising output but also as diminishing fluctuations; consequently neither the early mean nor its standard deviation is very meaningful when compared with more experienced groups. This point is illustrated in Figs. 1 and 2 where the output graph of a beginner is compared with that of the most variable operator in one of the upper experience groups.
Group (1).-This consisted of 26 operators in good health and with more than one year of experience.

If during a given week all the operator performances showed a rise or fall, the explanation would probably be some common factor such as material shortage, mechanical breakdown due to power failure, an emergency demand for high output, or perhaps the imminence of a holiday. During the period of study none of the first three situations arose nor did a close inspection of the records reveal any weeks in which the performance of all or most of the workers improved or deteriorated. All weeks can therefore be regarded as normal in this respect.

The data in Table 1 suggest that operators differ not only in average performance but also in their internal, i.e., within the operator, variability. Bartlett's test for homogeneity of internal variances yields a $\chi^{2}(25)$ of 126.5 ; this result is highly significant and shows that there are real differences between operators in respect of the size of their output fluctuations. It is interesting to observe that there seems to be no consistent relationship between average performance and its variability. Since the number of weeks of observation varies from operator to operator, it may also be stated - to clear the way for further analysis - that there does not appear to be any relation between the size of the internal variance and the length of the period of observation. One explanation for the heterogeneity of internal variances could be that some workers had long spells on the same material whereas others were more frequently switched between different yarns; this of course assumes that the O.P. formula did not make adequate allowance for such events. However, scrutiny of the records revealed no evidence that some operators were more favoured with " runs" of material than were others.

Since mule spinning is highly mechanized and because the operation of "piecing" is not a complex manual skill, one might expect that differences between individual operators would contribute little in the analysis of total variation. This point can be investigated if (while recognizing that for individuals its value may be substantially greater or smaller) the estimate of average internal variance of operators is accepted as meaningful.

TABLE 1

MEAN OPERATOR PERFORMANCE (O.P.) AND STANDARD DEVIATION IN 29 HEALTHY OPERATORS BY LENGTH OF EXPERIENCE

Piecing Experience

\begin{tabular}{|c|c|c|c|c|c|c|c|c|c|c|c|c|c|c|c|c|c|}
\hline \multicolumn{3}{|c|}{$\begin{array}{c}1 \text { st Year } \\
\text { (3 } \text { Operators) }\end{array}$} & \multicolumn{3}{|c|}{$\begin{array}{c}\text { 2nd Year } \\
(6 \text { Operators) }\end{array}$} & \multicolumn{3}{|c|}{$\begin{array}{c}\text { 3rd Year } \\
(5 \text { Operators) }\end{array}$} & \multicolumn{3}{|c|}{$\begin{array}{l}\text { 4th and 5th Years } \\
\text { (4 Operators) }\end{array}$} & \multicolumn{3}{|c|}{$\begin{array}{l}\text { 6th-14th Years } \\
\text { (6 Operators) }\end{array}$} & \multicolumn{3}{|c|}{$\begin{array}{c}15 \text { th Year or More } \\
\text { (5 Operators) }\end{array}$} \\
\hline $\begin{array}{l}\text { Mean } \\
\text { O.P. }\end{array}$ & S.D. & $\begin{array}{l}\text { Weeks } \\
\text { Observed }\end{array}$ & $\begin{array}{l}\text { Mean } \\
\text { O.P. }\end{array}$ & S.D. & $\begin{array}{c}\text { Weeks } \\
\text { Observed }\end{array}$ & $\begin{array}{l}\text { Mean } \\
\text { O.P. }\end{array}$ & S.D! & $\begin{array}{l}\text { Weeks } \\
\text { Observed }\end{array}$ & $\begin{array}{l}\text { Mean } \\
\text { O.P. }\end{array}$ & S.D. & $\begin{array}{l}\text { Weeks } \\
\text { Observed }\end{array}$ & $\begin{array}{l}\text { Mean } \\
\text { O.P. }\end{array}$ & S.D. & $\begin{array}{l}\text { Weeks } \\
\text { Observed }\end{array}$ & $\begin{array}{c}\text { Mean } \\
\text { O.P. }\end{array}$ & S.D. & $\begin{array}{l}\text { Weeks } \\
\text { Observed }\end{array}$ \\
\hline $\begin{array}{c}128.7 \\
133.7 \\
136.0 \\
= \\
=\end{array}$ & $\begin{array}{l}6 \cdot 6 \\
6 \cdot 2 \\
5 \cdot 2 \\
= \\
=\end{array}$ & $\begin{array}{l}15 \\
32 \\
38 \\
\\
\\
\end{array}$ & $\begin{array}{l}139 \cdot 3 \\
139.7 \\
138.7 \\
135.3 \\
136 \cdot 0 \\
136 \cdot 3 \\
\end{array}$ & $\begin{array}{l}3.2 \\
2.7 \\
4 \cdot 1 \\
7.6 \\
3.5 \\
4 \cdot 6\end{array}$ & $\begin{array}{l}39 \\
41 \\
41 \\
37 \\
34 \\
33 \\
\end{array}$ & $\begin{array}{l}141.9 \\
140.4 \\
140.0 \\
133.0 \\
140.2\end{array}$ & $\begin{array}{l}5 \cdot 4 \\
5 \cdot 2 \\
3.6 \\
6 \cdot 3 \\
5 \cdot 3 \\
-\end{array}$ & $\begin{array}{l}35 \\
39 \\
40 \\
34 \\
41 \\
\end{array}$ & $\begin{array}{c}140.0 \\
144.4 \\
143.8 \\
141.0 \\
=\end{array}$ & $\begin{array}{l}7 \cdot 2 \\
6 \cdot 0 \\
5 \cdot 0 \\
4 \cdot 2 \\
= \\
-\end{array}$ & $\begin{array}{l}36 \\
35 \\
36 \\
40 \\
\end{array}$ & $\begin{array}{l}149 \cdot 0 \\
151 \cdot 8 \\
142 \cdot 3 \\
144 \cdot 6 \\
139 \cdot 3 \\
138 \cdot 3\end{array}$ & \begin{tabular}{|l|}
3.3 \\
4.6 \\
3.6 \\
5.5 \\
2.9 \\
5.1 \\
\end{tabular} & $\begin{array}{l}32 \\
37 \\
21 \\
28 \\
18 \\
32 \\
\end{array}$ & $\begin{array}{l}142.5 \\
145.7 \\
149.0 \\
148.9 \\
140.4 \\
\end{array}$ & \begin{tabular}{|l|}
2.7 \\
5.8 \\
4.6 \\
6.1 \\
3.8 \\
\end{tabular} & $\begin{array}{l}20 \\
24 \\
39 \\
40 \\
41 \\
\end{array}$ \\
\hline \multicolumn{3}{|c|}{ Mean $\stackrel{\text { Gro }}{\mathrm{O} .}$} & \multicolumn{3}{|c|}{$\begin{array}{c}\text { Group } \\
\text { Mean O.P. 137.7 }\end{array}$} & \multicolumn{3}{|c|}{$\begin{array}{c}\text { Group } \\
\text { Mean O.P. 139.2 }\end{array}$} & \multicolumn{3}{|c|}{$\begin{array}{l}\text { Group } \\
\text { Mean O.P. } 142.2\end{array}$} & \multicolumn{3}{|c|}{$\begin{array}{c}\text { Group } \\
\text { Mean O.P. 145.0 }\end{array}$} & \multicolumn{3}{|c|}{$\begin{array}{c}\text { Group } \\
\text { Mean O.P. } 145.0\end{array}$} \\
\hline
\end{tabular}


Fig. 1.-The output chart of a woman operator, single, aged 26 years, in good health and starting work as a piecer.

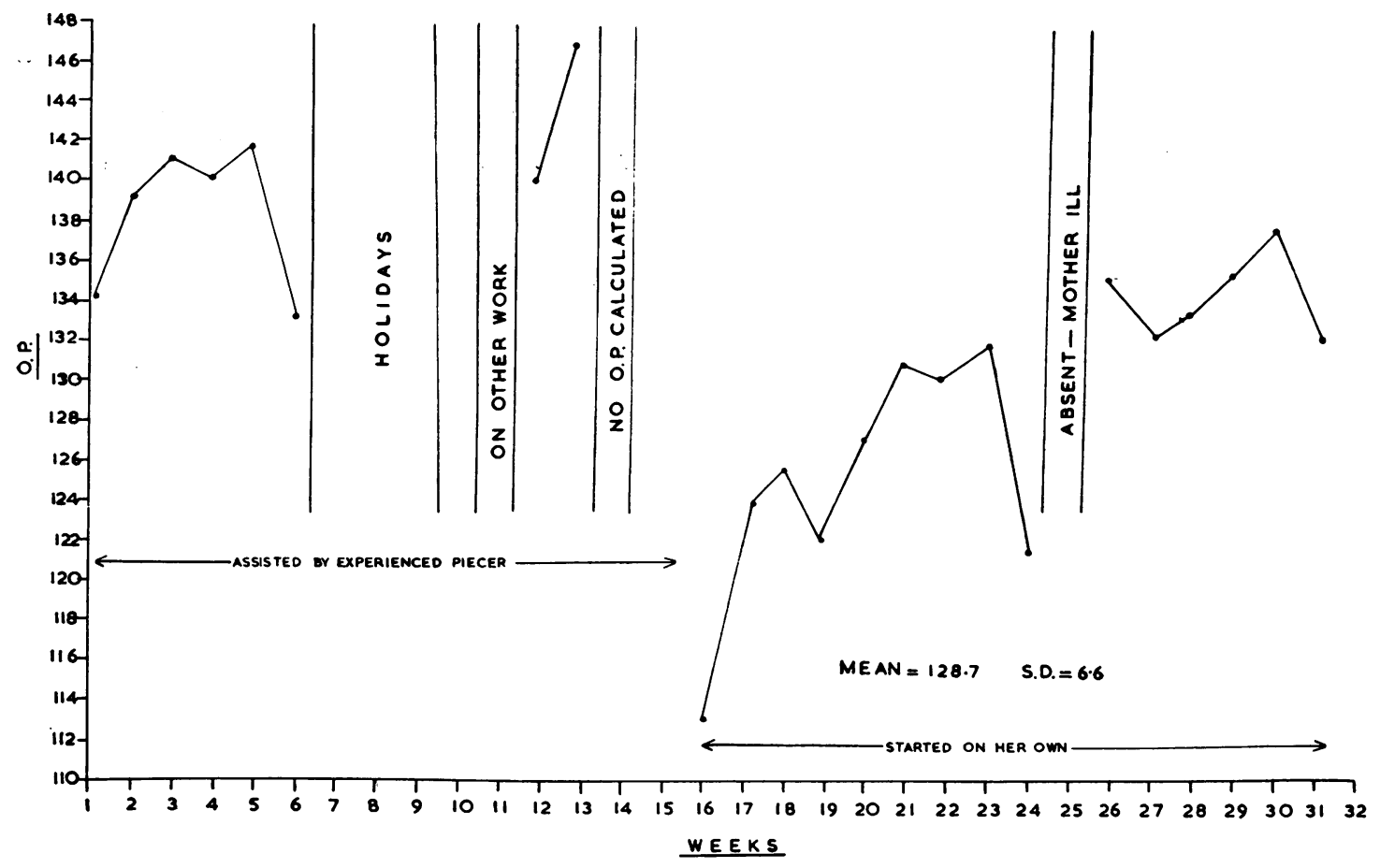

FIG. 2.-Output chart of a woman operator, married, aged 37 years, in good health except for bilateral varicose veins, with 10 years' experience.

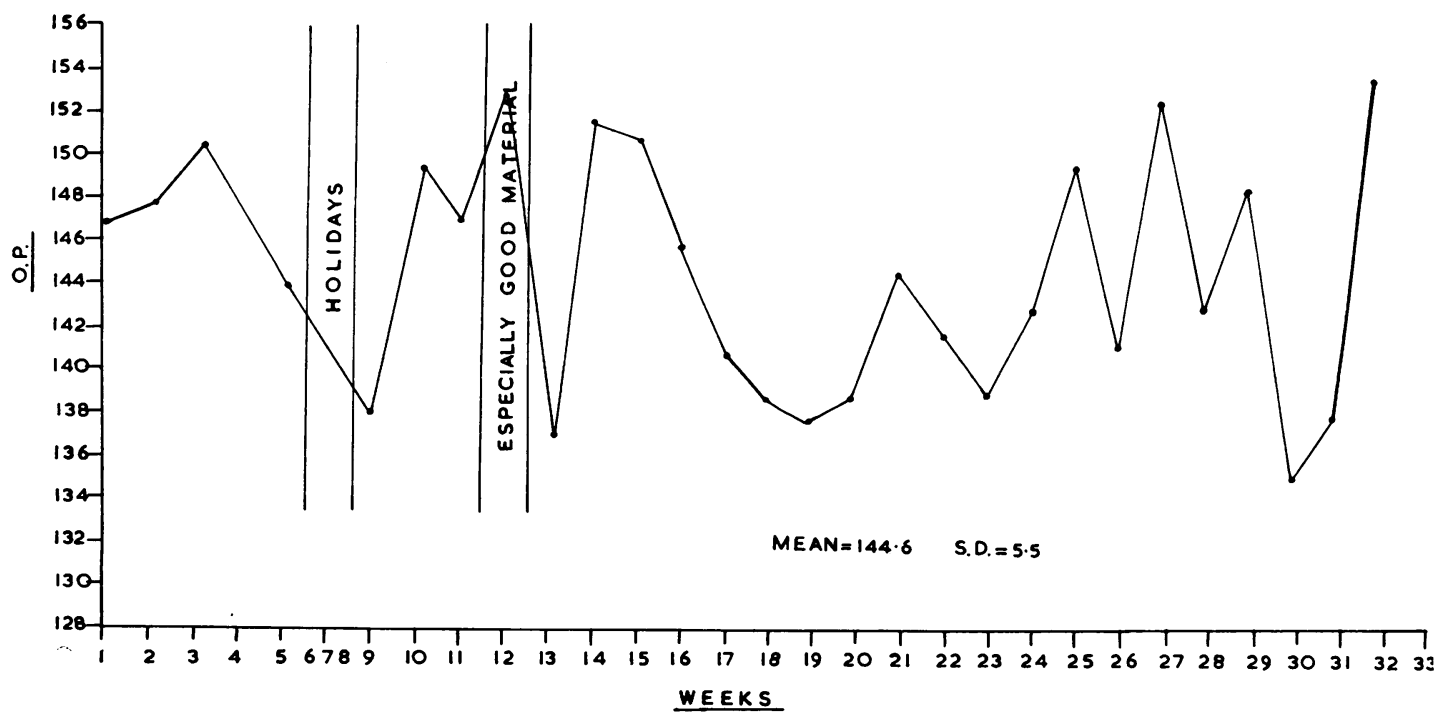


To allow for the influence of experience, the sum of squares attributable to differences between experience groups has been removed; Table 2 shows the partitioned sum of squares and the relevant mean squares.

TABLE 2

' OPERATOR PERFORMANCE' VARIATION OF 26 HEALTHY OPERATORS

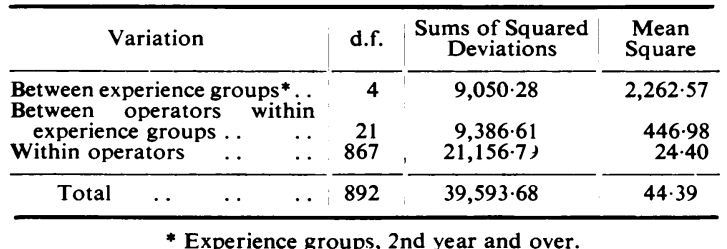

From this Table the average internal variance of an operator $\vec{\sigma}_{i}^{2}$ is estimated by $\vec{s}_{i}^{2}=24 \cdot 40$. Taking into account the varying number of weeks of observation (given in Table 1), there can be estimated the average component of variance, $\sigma_{b}^{2}$, attributable to differences between an operator's performance and the average performance of operators with similar experience; this component is $\mathrm{s}_{\mathrm{b}}^{2}=12 \cdot 32$. This latter component of variance is about $50 \%$ of the average internal variance of an operator and we therefore conclude that even in a highly mechanized process the differences between individual operators form a substantial part of total variation.

Since the conditions of work were uniform for the group and the 26 operators were in good health, we suggest that the foregoing differences in average output and internal variability point to real variations between

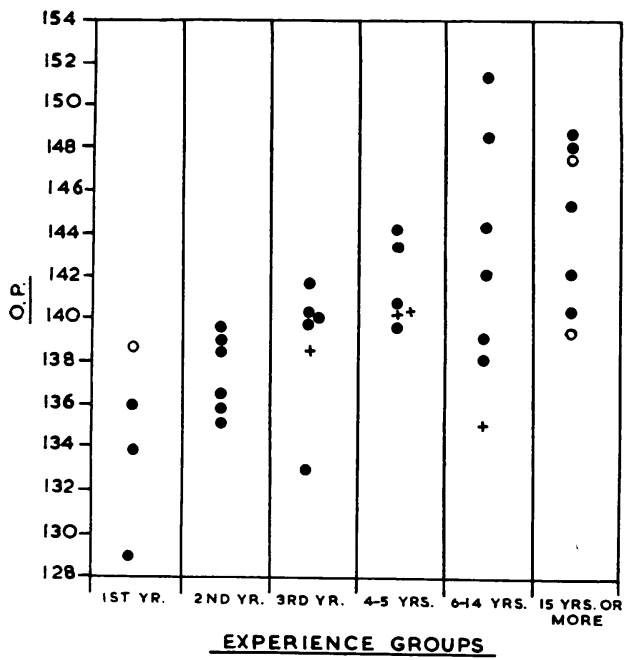

FIG. 3.-Comparison of healthy operators with selected group. - average O.P. = healthy groups.

O " , = impaired, healed, or disability.

$+\quad " \quad, \quad=$ pregnant operator. operators in respect of mental capacity and/or inclination for work.

The weekly records of output revealed no sign of lower or higher performance in the periods immediately before or after sickness absence from work. This was certainly true of short absences, most of which were due to upper respiratory ailments; there were very few cases of more serious illness, e.g., pleurisy, bronchitis, which had caused absence of several weeks, but even in these records no suggestion was found of a relationship between illness and output.

Group (2).-For convenience the three operators with physical handicap and the four pregnant girls are considered together. Fig. 3 shows the scatter of average O.P.s in experience groups.

The circle in the first year experience group denotes a girl who is totally deaf since birth but, though her training presented some difficulty, her deafness did not appear a handicap in the operation of piecing and she was regarded by the supervisors as a very competent worker.

The upper circle in the most experienced group is the mean O.P. of a 49-year-old woman absent for three weeks with hypertension and still under medical supervision at the end of the study. The lower circle is the mean output of a 65-year-old man with severe emphysema and chronic bronchitis who had to retire from work on health grounds soon after the study was completed.

Only one of the four pregnant piecers shows an output below the range of her experience group. A complication of pregnancy forced her to leave before the end of the investigation.

It appears that with two exceptions the performance of operators with a potential disability was not markedly different from the performance of the healthy group.

The observation that the average performance of the four pregnant operators was not lower than that of the others is by itself not evidence that performance was unaffected by pregnancy. In Table 3 are shown the mean O.P.s of these four operators before and during pregnancy.

TABLE 3

MEAN O.P. OF FOUR OPERATORS BEFORE AND DURING PREGNANCY

\begin{tabular}{|c|c|c|c|c|c|c|}
\hline $\begin{array}{l}\text { Piecing experience } \\
\text { No. of weeks } \\
\text { pregnancy .. }\end{array}$ & $\begin{array}{l}\text { (years) } \\
\text { rorked } \\
\ldots\end{array}$ & $\begin{array}{l}\text { in } \\
\ldots\end{array}$ & $\begin{array}{c}3 \\
13\end{array}$ & $\begin{array}{c}5 \\
26\end{array}$ & $\begin{array}{c}5 \\
12\end{array}$ & 13 \\
\hline $\begin{array}{l}\text { Before pregnancy } \\
\text { Mean O.P... } \\
\text { Weeks observed }\end{array}$ & $\cdots$ & $\cdots$ & $\begin{array}{c}136 \cdot 8 \\
29\end{array}$ & $\begin{array}{c}140 \cdot 0 \\
25\end{array}$ & $\begin{array}{c}139 \cdot 6 \\
5\end{array}$ & $\begin{array}{c}136 \cdot 0 \\
4\end{array}$ \\
\hline $\begin{array}{l}\text { During pregnancy } \\
\text { Mean O.P... } \\
\text { Weeks observed }\end{array}$ & $\because$ & $\because$ & $\begin{array}{c}139 \cdot 6 \\
12\end{array}$ & $\begin{array}{c}141 \cdot 8 \\
21\end{array}$ & $\begin{array}{c}141 \cdot 6 \\
7\end{array}$ & $\begin{array}{c}134 \cdot 8 \\
13\end{array}$ \\
\hline
\end{tabular}

From such slender data inference must be very tentative but it seems worthwhile to point out that, despite a good deal of pregnancy nausea and sickness, none of the operators showed any serious deterioration of output in early pregnancy. 


\section{Discussion}

If output is to be used as an index of mechanical, material, environmental, or individual variations, detailed knowledge of its formulation is essential. In this study the units of output were the product of elaborate work-study techniques adopted by the firm as the best basis for an incentive scheme. For that purpose the output measurements were satisfactory. It is well known that there are dangers in using records for purposes other than those for which they were designed and we have therefore been mindful of the possibility that the O.P. formula was not sufficiently sensitive to reveal an association between health and output.

From the data presented there is no evidence of a relationship between physical health and output. We have suggested that an important source of variation of output lies in differences between operators in respect of (a) experience and (b) attitudes and aptitudes. Had we been able to assess mental health over the study period our findings might have been more closely related to what, for lack of a more precise expression, may be termed " total health." Markowe and Barber (1952, 1953) have made important contributions to the relationship between mental health and productivity. Their findings show some of the complexities of this relationship and emphasize the need for more intensive studies of the influence of social background at home and at work. During our own study the senior foreman commented several times on the possible association between output and various domestic situations known to him, but in the absence of systematic inquiry this association could not be pursued.

Two final points merit attention. We could discern no sign of conscious restriction of output ; during 1954 demand for production was high, there were ample supplies of yarn for the spinning mules, and all piecework earnings were calculated on individual output. Secondly, there is the question of relationships between workers and management; in this firm there was a long and honourable tradition of employer-employee good will, evidence of which was provided by the ease and cooperation with which the work-study techniques were accepted in the spinning sheds. Throughout our period of observation, attitudes of mutual respect were so discernible that, though we have no specific data on morale, the existence of serious group discontent was unlikely. But we readily admit that, without a careful investigation similar to that of Davis (1953), appearances may have been deceptive.

The last conclusion from this preliminary study concerns the research opportunities afforded by good work-study schemes. Doctors with access to industries using these schemes are most favourably placed for the investigation of health factors in efficiency at workprovided always that the techniques and records are understood and their limitations appreciated.

\section{Summary}

The intra-individual and inter-individual differences of output have been studied in a group of 36 spinning mule operators, seven of whom had physical disabilities.

(1) From the data on those in good health it is suggested that variations in performance are likely to have been due to differences in capacity and inclination for work. The effect of experience is discussed.

(2) A group of three disabled and four pregnant workers had performances similar to the healthy group.

(3) No change of output could be discerned before or after sickness absence from work.

(4) The investigation points to the importance of studying mental health in relation to output.

We wish to thank the management of J. \& J. Crombie, Ltd., in particular Mr. N. Howarth of the Spinning Department, for generous cooperation. We are much indebted to Mr. S. Wyatt for helpful criticism.

\section{REFERENCES}

Davis, N. M. (1953). British Journal Industrial Medicine, 10, 18 Markowe, M., and Barber, L. E. D. (1952). Ibid., 9, 221 Wyat (1953). Ibid., 10, 125.

Wyatt, S. (1920). Industr. Fatigue Res. Board Report No. 7. (1944). Industr. Hlth Res. Board Emergency Report No. 5. 